\title{
Bioenergetic modelling of effects of fertilization, stocking density, and spawning on growth of the Nile tilapia, Oreochromis niloticus (L.)
}

\author{
KWANG MING LIU School of Natural Resources, University of Michigan, Ann Arbor, \\ Michigan, USA \\ WILLIAM Y. B. CHANG Division of International Programs, National Science \\ Foundation, Washington DC, USA and Center for Great Lakes and Aquatic Sciences, \\ University of Michigan, Ann Arbor, Michigan, USA
}

\begin{abstract}
A bioenergetic growth model was developed to examine the integrated effects of fertilization, stocking density, and spawning on the growth of tilapia, Oreochromis niloticus (L.), in pond aquaculture. The analyses showed that growth rates increase with higher levels of organic fertilization up to $500 \mathrm{~kg} / \mathrm{ha} /$ week. Growth rates increased with added food rations in ponds, reaching a maximum growth of $2.07 \mathrm{~g} /$ day at about $44-48$ days after stocking. Fish growth rates decreased with increased levels of stocking density. The stocking density for optimal growth is $1 \mathrm{fish} / \mathrm{m}^{2}$; the optimal density for total harvesting weight and fish size is $2 \mathrm{fish} / \mathrm{m}^{2}$. Model sensitivity analysis indicated that tilapia growth is most sensitive to catabolism (metabolism) and anabolism (synthesis) coefficients, both of which are geometrically related to the fish body weight. Food assimilation efficiency $(b)$ and the food consumption coefficient $(h)$ have a modest effect on fish growth. Spawning in grow-out ponds can have a major effect on fish growth.
\end{abstract}

\section{Introduction}

Pond richness, stocking density, and spawning can significantly influence fish growth in ponds. The levels and relative effects of each of the factors on the rates of fish growth in ponds are difficult to discern since many of these effects are dependent and interactive. In tilapia culture, this problem can be particularly significant since ponds are stocked at a density close to or beyond the pond carrying capacity. At these levels of stocking density, tilapia can sexually mature at an early age and leads to a condition called 'stunting', which frequently results in excessive recruitment, and reduces growth and yields of harvestable-size fish. The objective of this study is to develop a bioenergetic model to evaluate the relative effects of fertilization, stocking density, and spawning on tilapia growth, and to study the optimal conditions of tilapia growth and yield under different cultural conditions.

\section{Bioenergetic models}

A bioenergetic model was developed using the Ursin (1967) model, including factors such as fish size, rations, levels of fertilization, stocking density, and spawning.

Correspondence: K. M. Liu, Center for Great Lakes and Aquatic Sciences, University of Michigan, Ann Arbor, Michigan 48109, USA. 
Ursin (1967) generalized Putter's (1920) metabolic growth model, $\mathrm{d} w / \mathrm{d} t=\mathrm{H} w^{2 / 3}-k w$, to formulate the bioenergetic model as:

$$
\begin{gathered}
\mathrm{d} w / \mathrm{d} t=H w^{m}-k w^{n} \\
\text { (Growth }=\text { Energy intake }- \text { Energy output) }
\end{gathered}
$$

where

$w$ is weight

$t$ is time

$H$ is the coefficient of anabolism (synthesis)

$$
\left(\mathrm{g}^{1-m} / \text { day }\right)
$$

$m$ is the exponent of body weight for anabolism

$k$ is the coefficient of fasting catabolism (metabolism)

$$
\left(\mathrm{g}^{1-n} / \text { day }\right)
$$

$n$ is the exponent of body weight for fasting catabolism.

when $\mathrm{d} w / \mathrm{d} t=0$ gives

$$
w=W_{\infty}=\left(\frac{H^{l /(n-m)}}{k}\right)
$$

$w_{\infty}$ is an asymptotic weight.

Equation 1 can be combined with the works of Winberg (1956) and Ivlev (1961) Winberg's (1956) energy balance equation gives the growth equation:

$$
\mathrm{d} w / \mathrm{d} t=b \mathrm{~d} R / \mathrm{d} t-Q
$$

where $\mathrm{d} R / \mathrm{d} t$ is the ration ( $\mathrm{g} / \mathrm{day}$ ), $Q$ is the total metabolic rate (g/day), and $b$ is the efficiency of food assimilation. Ursin (1967) proposed modelling rations as:

$$
\mathrm{d} R / \mathrm{d} t=h f w^{m}
$$

where $f$ is the feeding level and is a function of fertilizer richness and population density, $0<f<1$, and $h$ is a coefficient of food consumption. Based on Ivlev's (1961) equation, the feeding level can be expressed as:

$$
f=1-\exp (-s p / N)
$$

where $s$ is a coefficient, $p$ is the fertilizer inputs, and $N$ is the number of fish. The total metabolic rate can be separated into two components - feeding catabolism and fasting catabolism (Ursin 1979)

$$
Q=a b \mathrm{~d} R / \mathrm{d} t+k w^{n}
$$

where $a$ is a fraction of food assimilation. Then equation 1 can be expressed as:

$$
\mathrm{d} w / \mathrm{d} t=(1-a) b h(1-\exp (-s p / N)) w^{m}-k w^{n}
$$

This equation considers fish growth and its relationship to the number of fish in ponds, fish sizes, and food concentration.

Tilapia, Oreochromis niloticus (L.), may spawn at an early age (3-6 months) before reaching the desired marketable size. In such cases, a portion of the fish's energy is diverted 
from increasing overall weight to increasing gonadal growth. In this study, since larvae were found in the ponds, the tilapia growth obtained from equation 7 was affected by the spawning behaviour. The growth equation without spawning effect can be modified as:

$$
\mathrm{d} w / \mathrm{d} t=(1-a) b h(1-\exp (-s p / N)) w^{m}-k w^{n}+s w
$$

where $s w$ is a ratio of larvae weight and fish weight.

\section{Parameter estimations}

The data used in this study were collected from 1985 to 1986 in Ayuthaya, Thailand by the Collaborative Research Support Program's (CRSP) global pond dynamics/aquaculture experiments. Two experiments, each covering a period of 5 months during either the wet or the dry season, were conducted each year. Detailed methods for pond preparation, stocking procedures, duration of experiments, and measurement methods are described in the CRSP Work Plan (CRSP 1985). The dry season data from the Thailand third cycle were used to estimate the parameters and the wet season data were used to validate the model. These data include the results of additions of four levels $(125,250,500$ and $1000 \mathrm{~kg} / \mathrm{ha} /$ week) referred to as levels 1, 2, 3 and 4 respectively of organic fertilizer (wet chicken manure) to the experimental ponds. The amount of fertilizer applied to the pond is used as the fertilizer richness in the simulation.

Ursin (1967) suggested $m=2 / 3$ and $n=5 / 6$ as reasonable starting values. However, we found that $m=2 / 3$ and $n=1$ is a better estimate based on the least square method.

If $m=2 / 3$ and $n=1$ in equation 2 then the growth equation can be integrated and expressed per Beverton \& Holt's (1957) equation as:

$$
w(t)=W_{\infty}\left\{1-\left.\exp \left[-K\left(t-t_{o}\right)\right]\right|^{3}\right.
$$

where $t_{o}$ is the time when $w(t)=0$ and $K$ is the growth coefficient of fish and $K=k / 3$. Equation 2 can also be simplified as $W_{\infty}=(H / k)^{3}$ and we get

$$
H=k\left(W_{\infty}\right)^{1 / 3}
$$

From equation 10, we can obtain $H$. Asymptotic weight, $W_{\infty}$, and growth coefficient, $K$, used for this computation are listed in Table 1.

Table 1. Asymptotic lengths, $L_{\infty},(\mathrm{cm})$, asymptotic weights, $W_{\infty},(\mathrm{g})$, growth coefficients, $K$, (per year), estimated coefficients of anabolism, $H,\left(g^{1-}-m_{/ d a y}\right)$, and estimated coefficients of fasting catabolism, $k$, ( $g^{1-n} /$ day $)$ for different fertilizer levels

\begin{tabular}{lccccc}
\hline $\begin{array}{l}\text { Fertilizer } \\
\text { levels } \\
(\mathrm{kg} / \mathrm{ha} / \text { week })\end{array}$ & ${ }^{*} L_{\infty}$ & ${ }^{*} W_{\infty}$ & ${ }^{*} K$ & $H$ & $k$ \\
\hline 125 & 26.0 & 318 & 3.88 & 0.218 & 0.0319 \\
250 & $24 \cdot 2$ & 228 & 5.69 & 0.286 & 0.0468 \\
500 & $27 \cdot 1$ & 372 & 4.60 & 0.272 & 0.0378 \\
1000 & $25 \cdot 8$ & 328 & 4.78 & 0.271 & 0.0393 \\
\hline
\end{tabular}

*From Springborn, Jensen \& Chang (in press) 
Caulton (1982) reported that the efficiency of food assimilation of tilapia ranges from 0.478 to 0.587 . We used the average value $(b=0.53)$ in this study. From equation $7, H$, the coefficient of anabolism, can be expressed as:

$$
H=(1-a) b h(1-\exp (-s p / N))
$$

Because data on fertilizer richness $(p)$ and fish density $(N)$ were available from the CRSP data, known values for the efficiency of food assimilation $(b)$, and for the coefficient of anabolism $(H)$ were obtained from equation 10, parameters $a, h$, and $s$ in equation 11 can be estimated using the non-linear regression method by substituting values of $H, b, p$, and $N$ into equation 11. We estimated the fraction of food assimilation, $a$, coefficient of food consumption, $h$, and the coefficient, $s$, as $0.435,0.997$ and 2.91 respectively.

\section{Simulation results}

The modified bioenergetic model considers the parameters of fish stocking density, fertilizer richness, and spawning, and closely fits the observed data for different fertilizer levels (Fig. 1 ). The estimated maximum growth rates and the number of days from stocking at which maximum growth occurs are 1.62 (48 days), 1.27 (22 days), 2.07 (48 days), and 2.06 g/day (44 days) for fertilization levels $1,2,3$ and 4 respectively. The average rations at which the maximum growth rates were found to be $6 \cdot 20,4.92,8.38$ and $7.85 \mathrm{~g} /$ day for four fertilizer levels respectively. The model simulation indicated that the optimal tilapia growth condition for stocking density and the addition of organic fertilizers is $500 \mathrm{~kg} / \mathrm{ha} /$ week with tilapia stocked at $1 \mathrm{fish} / \mathrm{m}^{2}$ and no spawning activity.

Figure 2 shows that the simulated growth curves (without spawning) fit the observed data (actual weight plus larvae weight) well. The spawning term, $s w$, in equation 8 can have significant impact on fish growth. In the CRSP experiments in Thailand, the larvae weights were found to be $7 \cdot 5 \%, 8.9 \%, 12.9 \%$ and $10.1 \%$ of body weight for levels $1,2,3$ and 4 respectively. If we assume that spawning loss is in the same proportion as larvae weight to body weight, the adult fish weight in this simulation may increase by the end of the experiment from $254 \mathrm{~g}$ to $293 \mathrm{~g}$ (level 1), $155 \mathrm{~g}$ to $188 \mathrm{~g}$ (level 2), $287 \mathrm{~g}$ to $448 \mathrm{~g}$ (level 3), and $271 \mathrm{~g}$ to $360 \mathrm{~g}$ (level 4$)$.

\section{Sensitivity analysis}

Sensitivity analysis was carried out to evaluate the relative importance of the parameters used in the models. The parameters values of $m, n, k, b$ and $h$ published for other fishes have been used in the simulations (Table 2). The sensitivity analysis was determined using equation 12 (Jensen 1991).

$$
T(p)=\left|\frac{\Delta(O) p}{\Delta(p) O}\right|
$$

where $\Delta(O)$ is changes in output, $\Delta(p)$ is changes in parameter, $O$ is the original output, and $p$ is the original parameter value (Jensen 1991). The results of sensitivity analysis are listed in Table 2. The order of sensitivity for the parameters is $n, m, b, h, k$ and $N$. ' $n$ ', the exponent of body weight for catabolism, is the most sensitive factor that affects fish growth (Fig. 3A). Changes in $m$ also have substantial impacts in growth rates. In particular, when $m$ is increased from 0.75 to $0 \cdot 8$, the simulated growth rates exhibited geometric increases (Fig. 3B). 


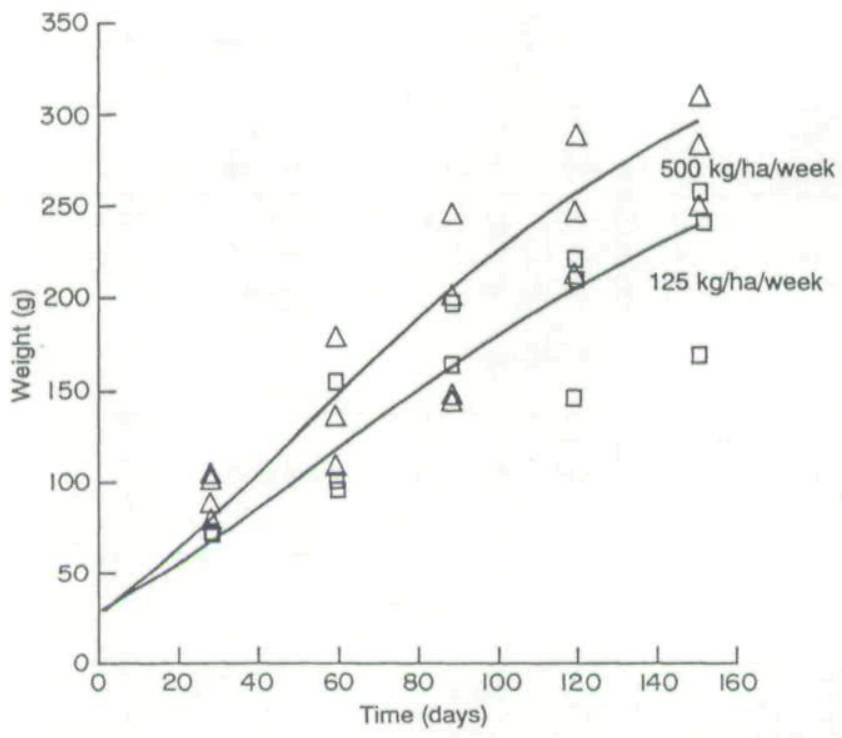

Figure 1. Simulated growth of tilapia for different fertilizer levels with modified bioenergetic model, $125 \mathrm{~kg} / \mathrm{ha} / \mathrm{week}$ and $500 \mathrm{~kg} / \mathrm{ha} /$ week, are shown here. $\square, \triangle$ : observations for $125 \mathrm{~kg} / \mathrm{ha} /$ week and $500 \mathrm{~kg} / \mathrm{ha} /$ week respectively.

Coefficients $m$ and $n$ are more sensitive than coefficient of catabolism $(k)$ for growth because the effects of $m$ and $n$ on growth are geometric while the effect of $k$ on growth is additive (Fig. $3 \mathrm{~A}, \mathrm{~B}$, and $\mathrm{E})$. Efficiency of food assimilation, $b$, and the coefficient of food consumption, $h$, have modest effects on tilapia growth (Fig. 3C and D). Stocking density can also affect fish growth. If an increase in fish density reduces the available fish rations and effects the adequate level of fish feeding, growth can decline (Fig. 3F).

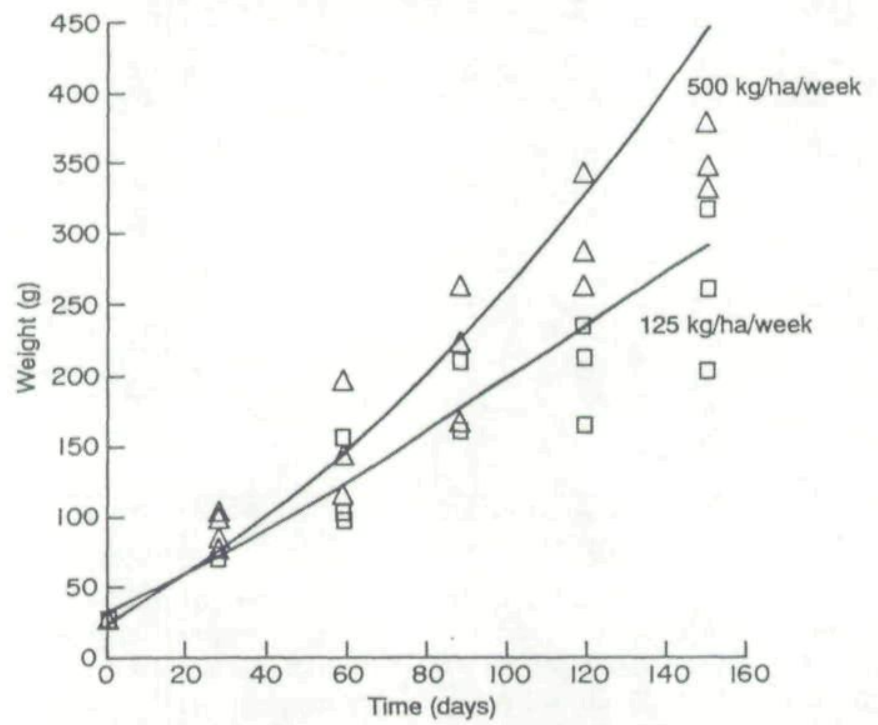

Figure 2. Simulated growth of tilapia without spawning activity for different fertilizer levels, $125 \mathrm{~kg} / \mathrm{ha} /$ week and $500 \mathrm{~kg} / \mathrm{ha} /$ week, are shown here. $\square, \triangle$ : actual weight plus larvae weight for $125 \mathrm{~kg} / \mathrm{ha} /$ week and $500 \mathrm{~kg} / \mathrm{ha} /$ week respectively. 
Table 2. Ranges of the growth parameters in literature and used in simulation and sensitivities related to the parameters

\begin{tabular}{lccc}
\hline Parameters & Literature & Simulation & $\begin{array}{c}\text { Sensitivity } \\
\text { (changes in folds) }\end{array}$ \\
\hline$n^{*}$ & $0 \cdot 75-1 \cdot 0$ & $0 \cdot 75-1 \cdot 0$ & $8 \cdot 80$ \\
$m^{*}$ & $0 \cdot 3-0 \cdot 75$ & $0 \cdot 5-0 \cdot 75$ & $4 \cdot 15$ \\
$b^{* *}$ & $0 \cdot 478-0.587$ & $0 \cdot 4-0 \cdot 6$ & 1.95 \\
$h^{*}$ & $0 \cdot 297$ & $0 \cdot 7-0.997$ & 1.92 \\
$k^{*}$ & $0 \cdot 0008-0.0216$ & $0 \cdot 02-0.045$ & 1.51 \\
$N$ & & $0 \cdot 5-4$ & 0.01 \\
\hline
\end{tabular}

*: From Ursin (1967), 81 species

**: From Caulton (1982), tilapia (Tilapia rendalli Boulenger)
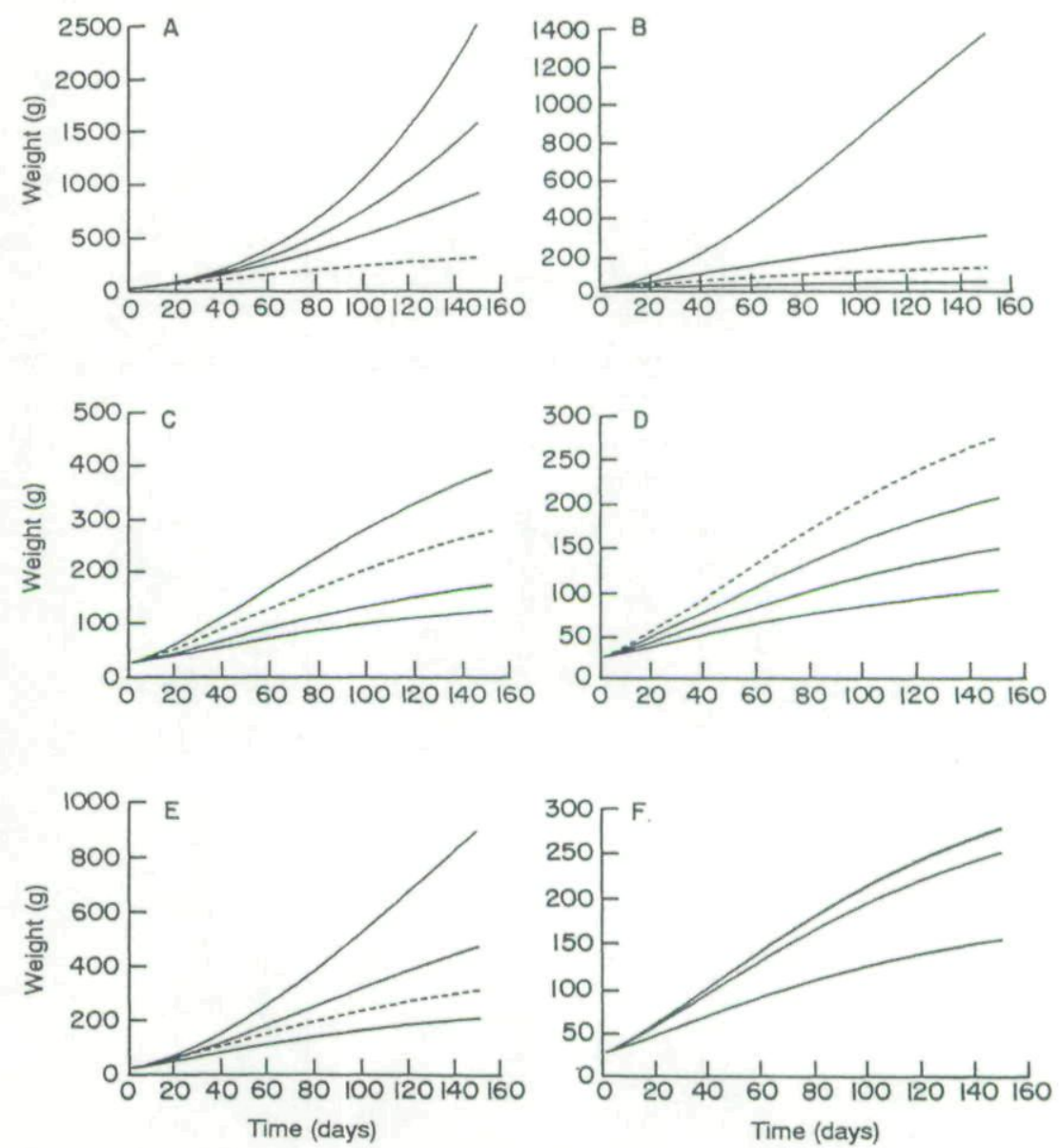

Figure 3. (A) Growth of tilapia with the change in the exponent of body weight in catabolism; from the top down $n=$ $0 \cdot 75,5 / 6,0 \cdot 9$ and $1 \cdot 0^{*}$. (B) Change in growth pattern with change in the exponent of body weight in anabolism; from the top down $m=0 \cdot 8,0 \cdot 75,2 / 3^{*}$ and $0 \cdot 6$. (C) Growth of tilapia with change in efficient of food assimulation; from the top down $b=0 \cdot 6,0 \cdot 53^{*}, 0 \cdot 45$ and $0 \cdot 4$. (D) Growth of tilapia with change in coefficient of food consumption; from the top down $h=0.997^{*}, 0.9$ and 0.8 and 0.7 . (E) Growth of tilapia with change in coefficient of catabolism; from the top down $k=0.02,0 \cdot 03,0.038^{*}$ and 0.045 . (F) Growth of tilapia with change in fish density; from the top down $N=0.5$, $1^{*}$ (overlapped), 2 and $4 \mathrm{fish} / \mathrm{m}^{2}$. *indicates the value we used in the simulation; ---indicates the growth curve we generated from the simulation. 


\section{Discussion}

Environmental and physiological factors are important in warmwater fish culture and can affect growth and yields substantially. Studies have reported the effects of stocking density, fertilizer richness, or spawning individually on fish growth (Hepher 1978; Diana \& Lin 1988; Green, Phelps \& Alvarenga 1989), but none as yet has evaluated the integrated effects of these factors on fish growth in ponds. In order to assess the integrated effects of stocking density, spawning, and fertilization richness on tilapia growth, we modified Ursin's (1967) model to develop a bioenergetic growth model. In addition to the above factors, this model also takes into consideration changes in fish size, rations and temperature. While temperature is not a major factor in this study (ambient temperature changes during the CRSP study were small), the effects due to such changes are not considered.

The best combination of the anabolism (synthesis) coefficient, $m$, and the catabolism (metabolism) coefficient, $n$, for tilapia was found to be $m=2 / 3$ and $n=1$. Anabolism is noted to correlate with fish $\mathrm{O}_{2}$ consumption, since fish are aerobic heterotrophs (Moreau 1987). The coefficient, $m$, was reported close to the ratio between gill surface area and body weight (Moreau 1987). The value obtained in this study, 2/3, is close to this ratio. As for $n$, since catabolism (metabolism) is directly proportional to fish weight, $n=1$ appears to be appropriate.

The maximum growth rates for tilapia in the ponds examined are found about $44-48$ days after stocking. Although the specific factors which influence the time at which maximum growth occurs is not known, we provided a way to estimate directly the period during which such growth is to occur, as illustrated below:

$$
W I=8 / 27((1-a) b h(1-\exp (-s p / N)) / k)^{3}
$$

where $W I$ is the period of maximum growth and is the inflection point of the growth curve.

The amount and types of food available in ponds, culture species, stocking size and density, and temperature are thought to have impact on maximum growth. Hepher (1978) indicated that when food is not a limiting factor, maximum growth is determined by intrinsic physiological character, whereas the specific growth rate is determined by the genetic characteristics of the fish and by the environment. Weatherley (1976) mentioned that gene, hormone, fat and protein dynamics are factors affecting maximum fish growth. Expansion of the maximum growth period of tilapia can be an efficient way to optimize fish yield in ponds. Springborn, Jensen \& Chang (in press) reported that if fish production cost per day is constant, the economic return for fish yield at harvest is at a maximum at this inflection point and decreases thereafter as fish continue to grow. The postponement of the inflection point in growth can be an important way to increase economic return.

Fertilization is commonly used to enrich pond water to increase natural food production and to provide additional organic matter for fish food (Chang 1988). Fish growth rates were found to be directly related to the amount of enrichment when ponds were low in nutrients. The effects of fertilization on fish growth were less noticeable in eutrophic pond environments (Chang 1988, 1989); in fact, eutrophic ponds receiving a large addition of organic fertilizers often develop early-morning oxygen deficits which lead to anoxic conditions at dawn (Chang 1989). In this study, we found no significant increase in the growth of tilapia with levels of organic fertilization greater than $500 \mathrm{~kg} / \mathrm{ha} /$ week in CRSP experimental ponds in Thailand. Stickney, Hesby, McGeachin \& Isbell (1979) indicated that T. nilotica had the best growth in ponds that had a history of high manuring rate. Therefore, the high eutrophic 
conditions which existed in those ponds prior to fertilization may be important for fish growth.

Fish stocking density is an important factor in aquaculture as it can affect natural food availability, the efficiency of food resource utilization in ponds, and total fish yields in ponds (Chang 1988). As the number of fish stocked in a pond increases, the amount of ration available to each fish decreases. A reduction in fish growth is likely to occur when the pond becomes resource limited. However, when food is sufficient to support fish growth tilapia production increases directly with the increase in stocking density (Edwards, Sinchumpasak, \& Tabucanon 1981; Turner, Sibbald \& Hemens 1986).

In this study, we found that tilapia has an optimal growth rate when the stocking density is below $1 \mathrm{fish} / \mathrm{m}^{2}$ and its growth decreases as the stocking density increases (Table 3). Similar findings were made by Diana \& Lin (1988), who also mentioned that the mean weight of fish decreases with the increase in stocking density from one fish $/ \mathrm{m}^{2}$ to three fish $/ \mathrm{m}^{2}$. Tilapia asymptotic weight decreases as stocking density increases, while total harvesting weight increases as stocking density increases from $0.5 \mathrm{fish} / \mathrm{m}^{2}$ to four fish $/ \mathrm{m}^{2}$ (Table 3, Fig. 4). If we consider stocking density for optimal harvesting and fish weight, two fish $/ \mathrm{m}^{2}$ appears to be the best choice, while if we only consider stocking density for optimal growth rate, one fish/ $\mathrm{m}^{2}$ is the best selection.

Tilapia can begin to spawn at 3-6 months of age and the spawning often persists for 19-21 days (Buddle 1984). Welcomme (1970) reported that reproduction as a result of stunting can occur when the fish switches from somatic growth to gametogenesis at the first maturity, and indicated that this phenomenon can take place when the fish encounter environmental changes and stress. In our simulation, we assumed that reproduction started 55 days after stocking ( 88 days after hatching) because larvae were found 59 days after stocking in the CRSP experiments in Thailand. The percentage of larvae weight in proportion to body weight increases with stocking time and with the amount of organic fertilizer up to the level of $500 \mathrm{~kg} / \mathrm{ha} /$ week (Table 4). The simulation result shows that growth significantly increases when no reproduction occurs and the growth curves generated from the simulation fit the observed weight (stocked fish weight plus larvae weight) well. The real mechanism stimulating the fish to shift from somatic growth to gonadal growth is unclear, but Pullin (1982) suggested that the reduction in oxygen availability for fish may be one possible factor which affects the metabolic pathway, causing nutrients to be channelled into gonadal products.

Our bioenergetic model was verified using an independent CRSP data set from cycle 3 of the wet season in Thailand. We found that the simulated growth curves are close to the

Table 3. Simulated yield $(\mathrm{kg} / \mathrm{ha})$, maximum growth rate $(\mathrm{g} /$ day) and body weight $(\mathrm{g})$ at harvest in different stocking densities

\begin{tabular}{lccc}
\hline $\begin{array}{l}\text { Stocking density } \\
\left(\text { fish } / \mathrm{m}^{2}\right)\end{array}$ & $\begin{array}{c}\text { Yield } \\
(\mathrm{kg} / \mathrm{ha})\end{array}$ & $\begin{array}{c}\text { Maximum growth } \\
\text { rate }(\mathrm{g} / \text { day })\end{array}$ & $\begin{array}{c}\text { Body weight } \\
(\mathrm{g})\end{array}$ \\
\hline $0 \cdot 5$ & 1291 & $2 \cdot 07$ & $286 \cdot 8$ \\
1 & 2655 & $2 \cdot 06$ & $285 \cdot 7$ \\
2 & 4657 & $1 \cdot 85$ & $258 \cdot 7$ \\
3 & 5614 & $1 \cdot 46$ & $207 \cdot 9$ \\
4 & 5768 & $1 \cdot 09$ & $160 \cdot 2$ \\
5 & 5545 & $0 \cdot 82$ & $123 \cdot 1$ \\
\hline
\end{tabular}




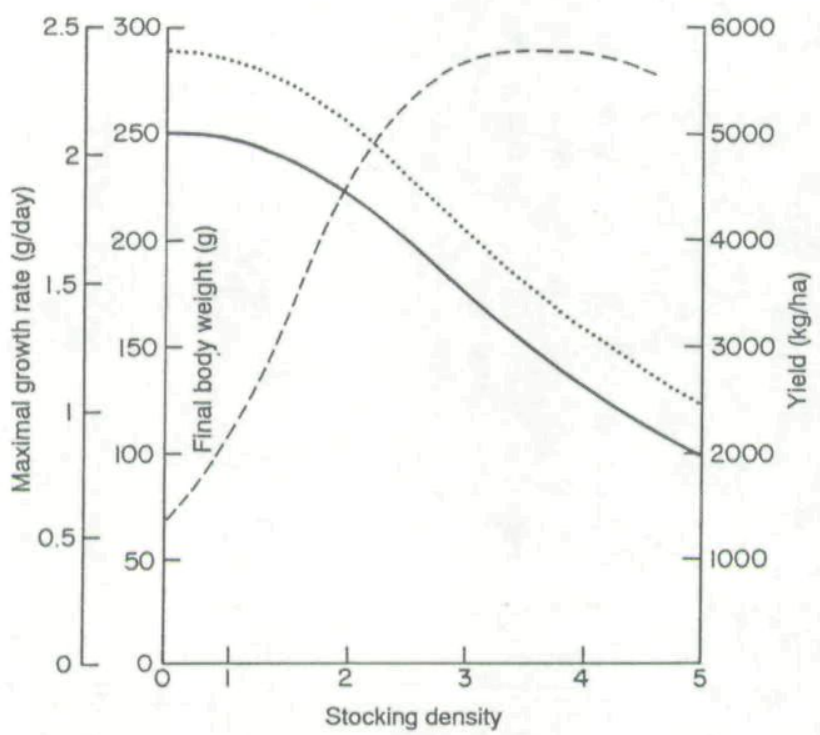

Figure 4. Simulated maximal growth rate $(\mathrm{g} /$ day), body weight $(\mathrm{g})$ and yield $(\mathrm{kg} / \mathrm{ha})$ at harvest in different stocking densities (fish $\left./ \mathrm{m}^{2}\right) .$, : maximal growth rate, $\ldots$ : final body weight, ---: yield.

observed data for all fertilization levels except level 3 (Fig. 5). Since the growth rates obtained from observed data for fertilization level 3 are lower than those of fertilization level 2 , the poor fit for the data from level 3 may be due more to variability in pond responses than to problems in model simulation. Overall, the modified bioenergetic model is accurate and can adequately describe the growth of tilapia for different pond conditions using the parameters estimated from a portion of CRSP Thailand data. This model, however, would produce optimal results if fish growth increased with fertilizer additions and there were no major trophic differences in pond history before fertilization. We found that the model simulation using a $90 \%$ survival rate provides the closest prediction of the observed tilapia yields.

Fish size and density, food concentration, and spawning have been considered individually in many pond experiments. Conducting such experiments is usually expensive and labour intensive, and at times it is not possible to replicate these experiments in ponds. The

Table 4. Percentage of larvae weight in proportion to body weight for different fertilizer levels. Inside parentheses are the larvae weights in $\mathrm{kg}$

\begin{tabular}{lcccc}
\hline \multirow{2}{*}{$\begin{array}{l}\text { Day after } \\
\text { stocking }\end{array}$} & \multicolumn{4}{c}{ Fertilizer levels $(\mathrm{kg} / \mathrm{ha} /$ week $)$} \\
\cline { 2 - 5 } & 125 & 250 & 500 & 1000 \\
\hline 28 & 0 & 0 & 0 & 0 \\
59 & $1 \cdot 5(0 \cdot 4)$ & $1 \cdot 3(0 \cdot 4)$ & $6 \cdot 0(2 \cdot 1)$ & $3 \cdot 3(1 \cdot 0)$ \\
88 & $6 \cdot 2(2 \cdot 4)$ & $4 \cdot 8(1 \cdot 3)$ & $9 \cdot 8(4 \cdot 5)$ & $8 \cdot 6(3 \cdot 9)$ \\
119 & $5 \cdot 9(2 \cdot 4)$ & $11 \cdot 1(5 \cdot 8)$ & $15 \cdot 8(10 \cdot 2)$ & $10 \cdot 9(6 \cdot 0)$ \\
150 & $14 \cdot 0(8 \cdot 3)$ & $15 \cdot 5(8 \cdot 8)$ & $20 \cdot 0(15 \cdot 4)$ & $17 \cdot 8(12 \cdot 0)$ \\
\hline
\end{tabular}



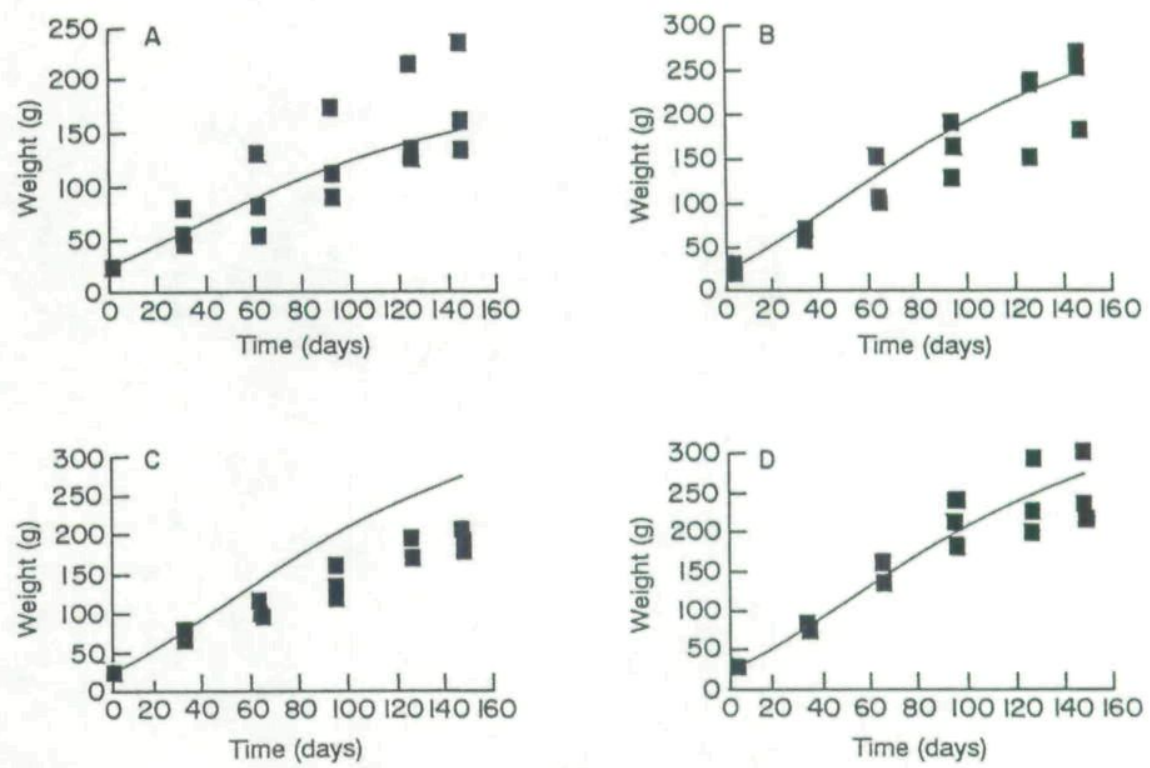

Figure 5. Simulated growth of tilapia for different fertilizer levels in wet season. A: $125 \mathrm{~kg} / \mathrm{ha} / \mathrm{week}, \mathrm{B}$ : $250 \mathrm{~kg} / \mathrm{ha} /$ week, C: $500 \mathrm{~kg} / \mathrm{ha} /$ week, D: $1000 \mathrm{~kg} / \mathrm{ha} /$ week. $\mathbf{m}$ : observations.

bioenergetic model developed in this study provides a synthesis of growth response to different conditions in ponds, considers the integrated effects of these factors on tilapia growth, and deduces a set of optimal cultural conditions for increasing tilapia yields.

\section{Acknowledgments}

This study was funded by a grant (No. DAN-4023-G-SS-2074-00) from the Pond Dynamics/ Aquaculture Collaborative Research Support Program (CRSP), Agency for International Development, and by the matching funds for the grant from the Office of Vice President for Research, the University of Michigan, to W.Y.B. Chang. Suggestions and comments from S. Schneider and A.L. Jensen are gratefully acknowledged. Contribution no. 547 of the Center for Great Lakes and Aquatic Sciences, the University of Michigan.

\section{References}

Beverton R.J.H. \& Holt S.J. (1957) On the Dynamics of Exploited Fish Population. Fishery Investigations (Series 2) 19, Ministry of Agriculture, Fisheres and Food, London.

Buddle R. (1984) Monosex tilapia fry production. International Center for Living Aquatic Resources Management ICLARM Newsletter 7, 4-6.

Caulton M.S. (1982) Feeding, metabolism and growth of tilapias: some quantitative considerations. In: The Biology and Culture of Tilapias (ed. by R.S.V. Pullin \& R.H. Lowe-McConnell), pp. 157-180. Conference Proceedings 7, International Center for Living Aquatic Resources Management, Manila, Philippines.

Chang W.Y.B. (1988) Fish production: Data synthesis and model development. In: Collaborative Research Support Program (CRSP), Pond Dynamics/Aquaculture Sixth Annual Administrative Report, pp. 41-49. Oregon State University, Marine Science Center, Newport, Oregon. 
Chang W.Y.B. (1989) Estimates of hypolimnetic oxygen deficits in ponds. Aquaculture and Fisheries Management 20, 163-172.

Collaborative Research Support Program (CRSP) (1985) Work Plan: Volume 3, Third Experimental Cycle. Pond Dynamics/Aquaculture CRSP, Oregon State University, Marine Science Center, Newport, Oregon.

Diana J.S. \& Lin C.K. (1988) The effect of stocking density of Oreochromis niloticus on the dynamics of aquaculture ponds. In: Collaborative Research Support Program (CRSP), Pond Dynamics/Aquaculture Sixth Annual Administrative Report pp. 25-27. Oregon State University, Marine Science Center, Newport, Oregon.

Edwards P., Sinchumpasak O.-A. \& Tabucanon M. (1981) The harvest of microalgae from the effluent of a sewage fed high rate stabilization pond by Tilapia nilotica. Part 2: Studies of the fish ponds. Aquaculture 23, 107-147.

Green B.W., Phelps R.P. \& Alvarenga H.R. (1989) The effect of manures and chemical fertilizers on the production of Oreochromis niloticus in earthen ponds. Aquaculture 76, 37-42.

Hepher B. (1978) Ecological aspects of warm-water fishpond management. In: Ecology of Freshwater Fish Production (ed. by S.D. Gerking), pp. 447-468. Blackwell Scientific Publications, Oxford.

Ivlev V.S. (1961) Experimental Ecology of the Feeding of Fishes. Yale University Press, New Haven, Connecticut. Jensen A.L. (1991) Simulation of fish population responses to exploitation. Ecological Modelling 55, 203-218.

Moreau J. (1987) Mathematical and biological expression of growth in fishes: recent trends and further developments. In: The Age and Growth of Fish (ed. by R.C. Summerfelt \& G.H. Hall), pp. 81-113. Iowa State University Press, Ames, Iowa.

Pullin R.S.V. (1982) General discussion on the biology and culture of tilapia. In: The Biology and Culture of Tilapia (ed. by R.S.V. Pullin \& R.H. Lowe-McConnell), pp. 331-351. Conference Proceedings 7, International Center for Living Aquatic Resources Management, Manila, Philippines.

Putter A. (1920) Studien uber physiologische Ahnlichkeit VI: Wachstumsahnlichkeiten. Pflugers Archiv Für die Gesamte Physiologie 180, 298-340.

Springborn R.R., Jensen A.L. \& Chang W.Y.B. (in press) Application of von Bertalanffy's equation to examine nile tilapia growth in aquaculture experiments. Aquaculture and Fisheries Management.

Stickney R.R., Hesby J.H., McGeachin R.B. \& Isbell W.A. (1979) Growth of Tilapia niloticus in ponds with differing histories of organic fertilization. Aquaculture 17, 189-194.

Turner J.W.D., Sibbald R.R. \& Hemens J. (1986) Chlorinated secondary domestic sewage effluent as a fertilizer for marine aquaculture. I. Tilapia culture. Aquaculture 53, 133-143.

Ursin E. (1967) A mathematical model of some aspects of fish growth, respiration, and mortality. Journal of the Fisheries Research Board of Canada 24, 2355-2453.

Ursin E. (1979) Principles of growth in fishes. Symposia of the Zoological Society of London 44, 63-87.

Weatherley A.H. (1976) Factors affecting maximization of fish growth. Journal of the Fisheries Research Board of Canada 33, 1046-1058.

Welcomme R.L. (1970) Studies on the effects of abnormally high water levels on the ecology of fish in certain shallow regions of Lake Victoria. Journal of Zoology 160, 405-436.

Winberg G.G. (1956) Rate of metabolism and food requirements of fishes. Minsk, Belorussian State University. [In Russian], 253pp. Translation Series 194, Fisheries Research Board of Canada, Ottawa, Ontario, 201 pp. 
This document is a scanned copy of a printed document. No warranty is given about the accuracy of the copy. Users should refer to the original published version of the material. 